\title{
ADOPTING DIGITAL TECHNOLOGIES INTO URBAN SETTINGS: TOWARDS SMARTER CITIES AND BETTER QUALITY OF LIFE
}

\author{
Mohammed Ali Berawi ${ }^{1 *}$, Perdana Miraj ${ }^{1}$, Mustika Sari ${ }^{1}$ \\ ${ }^{1}$ Center for Sustainable Infrastructure Development, Faculty of Engineering, Universitas Indonesia, \\ Depok 16424, Indonesia
}

\begin{abstract}
Major cities worldwide are now experiencing immense growth caused by rapid urbanization and industrialization over the past decades. Currently, more than half of the world's population lives in the urban area and this number is projected to increase most likely to more than $65 \%$ by 2050. Nowadays, Asia has the highest number of urban dwellers, which subsequently followed by Europe and Africa. Back in 2000, Tokyo was the largest metropolitan area occupied by 37 million citizens, followed by New Delhi, Shanghai, Mexico City, and Sao Paulo. Other cities such as Cairo, Mumbai, Beijing, and Dhaka caught up with average inhabitants of around 20 million people. Urbanization has been recognized as the driver that has given a huge contribution that helps increase the economic development in urban cities on a global scale. Despite its positive influences for economic growth, urbanization has led to various urban challenges including but not limited to congestion, urban sprawl, environmental degradation, limited job opportunities, housing, and public safety.
\end{abstract}

Along with the rise of information and communication technology (ICT) that is developing rapidly and disruptively in the past few years, traditional cities are changing by adopting the smart city concept aiming to address both its existing problems and future challenges. Even though there is no consensus yet among academics and policymakers about the definition of smart city concept, most of them agreed that smart city is a city development and management by considering the adoption of ICT in order to connect, monitor, and control various resources inside the city in an efficient and effective manner to optimize services for the people in performing their daily activities and to address the urban challenge. In general, a smart city should be seen more as an integrated system of sensors and processors integrated within the city's infrastructure network rather than the employment of ICT specifically in a particular city domain. The concept of a smart city is currently presented as the solution to urban challenges by coming up with new innovations to solve the mounting problems faced by urban cities to make cities better connected and more efficient in terms of connection, coordination, usage of resources, resiliency and sustainability.

There is an equilibrium between social, economic, and technological aspects that needs to be considered in developing smart city for it to be able to meet its dwellers' expectations regarding the city management to address challenges that come along with the new technologies. To put it another way, the digital technology adoption as the key element of smart city concept should be able to improve the quality of the city and the life of its dwellers without making further burden for them that can come in the form of digital security, privacy concerns, data traffic, limited access, etc.

*Corresponding author's email: maberawi@eng.ui.ac.id 
Extensive use of digital technologies in people's daily activities nowadays have increased massive volumes of data generated from urban infrastructure (e.g., energy, transport) and its dwellers (e.g., household energy output, the pattern of daily commuting). These data - widely known as Big Data, have been evolving in the past decades in terms of concept, benefits, and areas of application. In order to address challenges in the development of smart city concepts regarding the technology engagement, many academics have attempted to explore the combination of Big Data with other technology advancements including the Internet of Things (IoT), Machine Learning, Blockchain and Artificial Intelligent (AI). Comprehension of the correlation between these digital technologies will be useful in expanding the body of knowledge and in proposing added value for urban development. Knowledge expansion in this area can enable stakeholders in various fields to formulate strategic decisions in the decisionmaking process.

\section{Coupling Technology Adoption in Engineering and Social Sciences}

Technology adoption has been used in various research areas in order to stimulate added value and innovation. In this edition, the CSID Journal of Infrastructure Development presents nine papers dedicated to studies in engineering and social sciences adopting technology and innovative solutions to cope with dynamics in disruptive era.

The first paper, written by C. Villiers attempts to investigate patterns of drivers' behavior during rainfall events using different geometries. The findings show that heavy rainfall intensity has a significant impact on speed where on average, drivers reduced their speed 6 to $12 \mathrm{mph}$.

The second paper, written by V. Mandasari and E.T. Wahyuni, discusses the trend of publicprivate partnership (PPP) in Indonesia between 2002 and 2019. The result shows that the publications regarding PPP in the country are still limited compared to neighboring countries such as Singapore, Malaysia or Thailand. Some of the publications are still focusing on infrastructure such as roads and water supply, while research dealing with accounting reports, accountability, PPP taxation issues as well as the sociological issues remain rare.

The third paper, written by Wisundanto, B.M. Ramadhan, T. Widiastuti, I. Andi, and M.U. Al Mustofa, analyses product diversifications of insurance companies as supporting facilities for infrastructure development. The results of their research indicate a company's policy to possess lower levels of product diversification optimally leads to the generation of higher profits.

The fourth paper, written by P.A. Danarahmanto, and Y. Aziz, exposes the effect of entrepreneurship orientation, innovation, customer participation, business model, and sustainable performance on startup companies. Their findings show that digital startup companies are not future-oriented and will be more vulnerable to failure when only considered users as a source of income. Business models of a company in this era suggested that being flexible enable them to cope with the dynamics of competition.

The fifth paper, written by F.T. Resty, Y. Aziz and U. Kaltum, provides an overview of how technology and innovative ambidexterity may shape the digital infrastructure, particularly in Indonesia as a developing country.

The sixth paper, written by F. Ananda, discusses how fiber technology might strengthen the concrete slab to reduce crack and fire resistance. The fiber effect indicates a slowing of the crack width openings by the gradual addition of load, as occurs in concrete with the addition of $4 \%$ and $5 \%$ fibers.

The seventh paper, written by P. Miraj, A. Dofir, M.A. Berawi, and S.B.B. Abd Karim, investigates the progress of value engineering studies in Indonesia. The result of this paper shows that value engineering is still lacking publication and practice compared to other 
neighboring countries such as Singapore, Malaysia, or Thailand and developed countries such as United States, Japan or European Union members.

The eight paper, written by A.K. Zaini, shows an overview of how transportation is linked with sustainability issues to generate a better environment for the citizen and their quality of life in the longer term.

The ninth paper, written by B. Ryan, E. Koltsakis and P. Manoleas, promotes the use of lighter structural engineering that offers better economical features. Their research explores the innovative solutions of structural elements composed of thin-walled plates for the application on a lattice support structure of wind turbines.

We hope that this edition of the CSID Journal of Infrastructure Development may provide insightful knowledge and bring benefits to our readers. We welcome any comments or inquiries that you may have concerning the direction and the content of the journal. We also invite you to join us by sending your work for future consideration.

Warmest regards from Editorial Office,

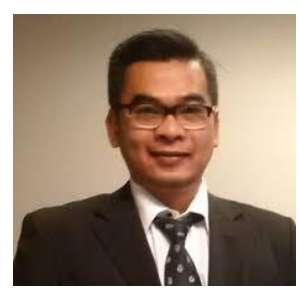

Dr. Mohammed Ali Berawi Editor-in-chief

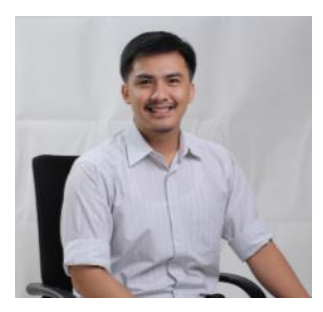

Perdana Miraj Managing Editor

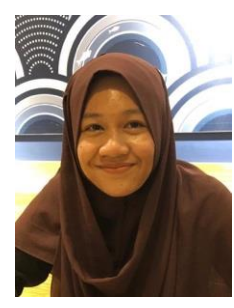

Mustika Sari Managing Editor 